\title{
A ESCOLA E 0 ADOLESCENTE EM CONFLITO COM A LEI: DESVELANDO AS TRAMAS DE UMA DIFÍCIL RELAÇÃO
}

\author{
Eliseu de Oliveira Cunha" \\ Universidade Federal da Bahia (UFBA) \\ Maria Virgínia Machado Dazzani”* \\ Universidade Federal da Bahia (UFBA)
}

RESUMO: O presente artigo teórico propõe-se a elencar e discutir possíveis razões da inamistosidade que, de modo geral, tem caracterizado a relação entre a escola e o adolescente em conflito com a lei no Brasil. Para tanto, empreendeu-se uma cuidadosa busca na literatura pertinente ao tema no intuito de desinvisibilizar e analisar criticamente os processos históricosociais dos quais essa tendência é tributária. O histórico alinhamento da escola com a cultura das classes abastadas, correlato à sua típica repulsa pelos estratos populares, revelou-se a espinha dorsal do fenômeno, uma vez que a maioria dos adolescentes em questão advém dessa classe social, sendo alvo privilegiado dos preconceitos, estigmas e estereótipos tipicamente atribuídos aos jovens de baixa renda. Para a atenuação desse quadro, a requalificação das práticas escolares para um efetivo acolhimento do adolescente mostra-se imprescindível.

Palavras-chave: Adolescentes em conflito com a lei. Medidas socioeducativas. Desigualdade educacional. Desigualdade social.

http://dx.doi.org/10.1590/0102-4698144008

"Graduando em Psicologia na Universidade Federal da Bahia (UFBA) e membro do Núcleo de Estudos sobre Desenvolvimento e Contextos Culturais (UFBA/CNPq), onde foi bolsista de iniciação científica (CNPq). E-mail: eliseuocunha@gmail.com.

" Doutora em Educação pela Universidade Federal da Bahia (UFBA). Professora Pesquisadora do Programa de Pós-Graduação em Psicologia (PPGPSI) e do Programa de Pós-Graduação em Educação (PGEDU) da UFBA. Pesquisadora líder do Núcleo de Estudos sobre Desenvolvimento e Contextos Culturais (UFBA/CNPq). E-mail: dazzani@ufba.br. 


\section{SCHOOL AND ADOLESCENTS IN CONFLICT WITH THE LAW: REVEALING THE PLOTS OF A DIFFICULT RELATIONSHIP}

ABSTRACT: This theoretical paper proposes to list and discuss possible reasons for the unfriendliness that, in general, has characterized the relationship between schools and adolescents in conflict with the law in Brazil. To this end, a careful research in the literature concerning the matter was accomplished in order to make this subject visible and analyze critically the historical and social processes from where this tendency came. The historic school alignment with wealthier classes' culture correlated with its typical repulse by low income's class proved to be the backbone of the phenomenon. The majority of these adolescents come from poorer social classes, being the priority target of prejudice, stigma and stereotypes typically assigned to low-income youth. To mitigate this situation, requalification of school practices is required for an effective acceptance of adolescents.

Keywords: Adolescents in conflict with the law. Socio-educative measures. Social inequality. Educational inequality.

\section{INTRODUĈ̣̃O}

A relação entre a escola e o adolescente autor de ato infracional é marcada por diversas tensões e ambiguidades. A literatura é eloquente em evidenciar que a maioria dos adolescentes que cometem práticas delituosas não frequentava a escola à época de sua apreensão, bem como em situar a evasão e o atraso escolar como preditores da delinquência juvenil (GALLO; WILLIAMS, 2005; 2008; FUCHS, 2009; SILVA, 2009; UNICEF, 2009; DIAS; ONOFRE, 2010; RODRIGUES; CRUZ, 2010; ZANELLA, 2010; OLIVEIRA, 2011; ZANELLA, 2011).

As leis que versam sobre a atenção ao adolescente infrator têm sido unânimes em prescrever a frequência à escola e a participação em atividades pedagógicas como aspectos-chave para o afastamento da criminalidade e a reabilitação no convívio social (BRASIL, 1927; 1979; 1990; 2012). Entretanto, muitos educadores são resistentes em aceitar um estudante que praticou infração, alegando medo e falta de preparo. Além disso, via de regra, não há, nas instituições escolares, um clima amistoso ou favorável à inclusão desse aluno, sobre o qual não raro recaem processos de discriminação e hostilização (ASSIS, 1999; GALLO; WILLIAMS, 2005; TOREZAN, 2005; GALLO; WILLIAMS, 2008; TEIXEIRA, 2008; UNICEF, 2009; DIAS, 2011; PAULA, 2011).

Este artigo tem por objetivo discutir possíveis razões da inamistosidade que, de modo geral, caracteriza a interação entre a escola e o adolescente em conflito com a lei no Brasil, a partir da análise crítica dos processos histórico-sociais dos quais é tributária. Dois fatos 
justificam a realização desta reflexão teórica. O primeiro é a seriedade do tema, pois, sendo o acesso e a permanência à escola pública direito de todos e dever do Estado (BRASIL, 1988; 1990), qualquer postura aversiva e segregadora mantida pela escola estaria em frontal contrariedade ao seu papel inclusivo e cidadão. Em segundo lugar, a despeito da profusão de estudos que se debruçam sobre a interface entre escola e adolescência infratora, grande parte apresenta natureza descritiva e constatativa, propiciando apenas uma visão geral dessa complicada relação. São escassos os estudos que constroem hipóteses teórico-explicativas sobre as prováveis raízes sociais, históricas e políticas do fenômeno, tarefa à qual nos propomos no presente texto.

$\mathrm{O}$ artigo está estruturado em cinco partes. A primeira evidencia como a educação se estabelece nos sistemas jurídico-penais ocidentais como a principal ferramenta no tratamento da delituosidade juvenil. À segunda parte coube realçar como a escolarização formal se torna um evento obrigatório na trajetória infantojuvenil e um requisito fundamental para a inserção no mercado de trabalho. A terceira explana sobre como os jovens de origem popular ficaram em desvantagem escolar e, por conseguinte, laboral, afora o impacto desse fator na sua adesão à criminalidade. Na quarta parte é traçado um panorama dos diversos fenômenos que fazem da escola um ambiente adverso e desfavorável à inclusão e ao êxito acadêmico do adolescente infrator, analisando-se as reverberações dos processos discutidos nas partes anteriores. $\mathrm{Na}$ quinta parte, tecemos algumas considerações conclusivas e propositivas em torno do tema.

\section{EDUCAC̣ÃO: A ESPERANC̣A CONTEMPORÂNEA PARA A CORREC̣ÃO DAS CONDUTAS DELITIVAS JUVENIS}

O cometimento de delitos por adolescentes é um fenômeno presente nos diversos períodos históricos da grande maioria das sociedades, atravessando as fronteiras do tempo e do espaço (SOUZA NETO; CENTOLANZA, 2010). A preocupação social e estatal com essa prática também é remota, isto é, simultaneamente à evolução da delinquência juvenil, avança a inquietação do homem em equacioná-la (ESCANDON, 2006). Tal dinâmica assume contornos decisivos na contemporaneidade ocidental, quando, com a expansão da indústria, da urbanização e da população, assiste-se a um aumento vertiginoso da criminalidade precoce, impulsionada por problemas, como a miséria, o desemprego, a desabitação, a orfandade e a escassez generalizada de oportunidades, que configuravam o cenário 
de horror no qual milhões de crianças e adolescentes se desenvolviam (CARIDE, 2004). Diante da magnitude do caos social instaurado, governantes de várias nações passaram a implementar políticas de proteção, assistência e educação aos jovens das classes pauperizadas a partir do final do século XIX.

No Brasil, esse era o panorama da Primeira República, quando tomava corpo um complexo aparato assistencial-correcional destinado aos menores ${ }^{1}$. Este último, aponta Rizzini (1997 apud OLIVEIRA, 2010), visava: à prevenção (pela vigilância do menor e seu apartamento das influências "deletérias", que poderiam levá-lo a delinquir), à educação (pelo treinamento do menor para o trabalho e para a submissão às regras do "bem viver"), à recuperação (pela remoção do menor das teias sociais da ilicitude e sua "reabilitação" para o convício social) e à repressão (pela contenção do menor, impedindo-o de causar novos danos). Passadas algumas décadas e muitas transformações sociais, a atual lei que delibera sobre o atendimento a adolescentes infratores - Lei 12.594/12 - ratifica a crucialidade da educação no processo de recondução do adolescente aos caminhos da legalidade (BRASIL, 2012).

No transcorrer da história, a educação vem se consolidando como a principal ferramenta corretora das condutas delitivas juvenis, consolidação tributária de um otimismo pedagógico que invade o sistema jurídico-penal no início do século XX, cuja elucidação requisita a realização de um parêntese. Ariès (1981) assinala que, na modernidade, a criança, devido a seus trejeitos espontâneos e despudorados, passa a ser considerada pelos jesuítas um "esboço grosseiro do homem racional” (GRATIEN, 1646 apud ARIÈS, 1981, p. 162), cuja condição de puerilidade e selvageria exigia superação, dando lugar a atitudes morais e racionais. A imaturidade da criança insinuava sua maior suscetibilidade à incorporação de conteúdos e uma maior moldabilidade de seu caráter, nuances endossadas na contemporaneidade por ciências como a biologia, a pediatria e a psicologia, que passavam a produzir diversos saberes sobre a criança - e, mais tarde, sobre o adolescente - e suas particularidades etárias (ARIÈS, 1981).

Alçada ineditamente pelo catolicismo moderno a um patamar especial da condição humana, posteriormente requalificado pela ciência e suas descobertas sobre as especificidades físicas e psíquicas do ser em desenvolvimento, a tenra idade passa a ser concebida como um terreno fértil para a prevenção e o controle comportamental. Tratava-se de uma atraente perspectiva de regulação de condutas para o governo brasileiro da República Velha, pois muitos dos que "ameaçavam" a ordem social pertenciam a essa faixa etária. Um 
otimismo pedagógico começa a operar no bojo das políticas públicas para a população infantojuvenil. Segundo Rizzini (1997 apud OLIVEIRA, 2010), considerada um patrimônio valioso da nação, uma chave para o futuro, via-se na infância, ainda facilmente moldável, a solução para o país. Salvar a criança seria salvar a nação. Essa concepção já aparecia no discurso de pensadores como Comenius "toda esperança de um mundo melhor está baseada unicamente na educação da juventude" (MANACORDA, 1992, p. 222) e Erasmo de Roterdã - "a principal esperança das nações reside na educação da sua juventude" (SILVA, 2008, p. 39).

A tese de que os anos que antecedem a vida adulta são os mais propícios à instrução e à correção alcança a justiça penal no século XIX, quando, com a equiparação da criança e do adolescente a seres ontologicamente xucros, dada sua natureza primitiva, inaugura-se o fundamento teórico de uma nova justiça, baseada na "compreensão do rebento como um ser corrompido pela irracionalidade e destinado a ser objeto da atitude salvadora da educação corretiva, essencial para transmudá-lo à verdade da condição humana, a retidão moral" (GOMES, 2009, p. 79). O triunfo dessa linha de pensamento se traduz na sistemática criação de leis e órgãos de justiça específicos para crianças e adolescentes em diversos países a partir do século XX, em uma tendência mundial de afastamento dos menores das cortes ordinárias, da regência do direito penal e de sua submissão a legislações próprias. Essa marcha culminou na elevação da maioridade penal para idades entre 16 e 18 anos, aquém das quais a ênfase já não era mais punir o infrator, e sim corrigi-lo, educando-o para a não reincidência (GOMES, 2009).

Fechado o parêntese e tendo explicitado as razões pelas quais à ação educativa vêm-se delegando a missão de corrigir os adolescentes que infringem a lei, torna-se oportuno discutir o papel que a educação escolar, em sua especificidade, passa a desempenhar nesse processo.

\section{ESCOLA: A ETAPA OBRIGATÓRIA DA PREPARAC̣ÃO DO INDIVÍDUO PARA A VIDA SOCIAL E LABORAL}

Illich (1985) chama a atenção para a realidade educacional das eras antiga e medieval, quando inexistia a escola nos moldes que atualmente a caracterizam. Aprendia-se no dia a dia, por meio da escuta das ensinanças dos adultos e da observação, imitação e participação em suas atividades laborais e culturais, sem formalidades ou regulamentações. Todavia, sublinha Manacorda (1992), a modernidade testemunha uma mudança radical na educação, que de fato privado 
se converte em questão pública, porquanto, até então circunscrita ao meio familiar e comunitário, passa a ocupar uma instituição própria (a escola) e a ser confiada a especialistas (os professores), agentes de um sistema de ensino burocrático, hierarquizado e segmentado.

Três fenômenos históricos deram impulso ao estabelecimento da escola como palco oficial da instrução acadêmica. O primeiro foi o reposicionamento do lugar social do infante operado pelos jesuítas modernos e atualizado por cientistas contemporâneos, sinalizando para um ser ingênuo, rudimentar e mais vulnerável à assimilação de conhecimentos e à disciplina. $\mathrm{O}$ segundo foi o entusiasmo pedagógico herdeiro direto dessa tendência, a qual animou várias reformas educacionais que tinham como alvo o novo ser em condições ótimas de aprendizado. Por último, pode-se destacar as transformações sociais da idade contemporânea, com as quais os governos tiveram que sintonizar seus sistemas educacionais. A revolução industrial, advoga Carlos (2013), foi a principal delas, requisitando do grosso da população habilidades mínimas de leitura, escrita e efetuação de cálculos, em vistas ao competente manejo de ferramentas e máquinas, bem como a uma efetiva inserção nos circuitos sociais do trabalho e do consumo. Ora, se a humanidade dispunha de indivíduos aptos e predispostos à aprendizagem, de demandas sociolaborais em consonância com as quais educá-los e de uma crescente confiança no êxito desse projeto formativo, estava preparado o terreno para a consolidação da escola. Não por acaso, Manacorda (1992) pontua que, a partir do século XIX, vários países instituem seus sistemas públicos de ensino, bem como as leis e diretrizes que orientam a escolarização. No Brasil, a educação como direito social foi consagrada pioneiramente na Constituição de 1988, que a tornou obrigatória dos 4 aos 17 anos, convocando o Estado a ofertála gratuita e universalmente (BRASIL, 1988), em harmonia com a Convenção sobre os Direitos da Criança, declarada pela Organização das Nações Unidas um ano depois (ONU, 1989).

A educação escolar ascende, postula Illich (1985 apud TUNES; PEDROZA, 2011), ao estatuto de monopólio radical. Para ele, enquanto que no monopólio comum há uma redução ou restrição da liberdade do indivíduo, no monopólio radical impera o paradigma da via de mão única, isto é, da alternativa exclusiva e soberana. O autor nos brinda com um exemplo do setor econômico, no qual o monopólio implica o controle exclusivo, por uma companhia, dos meios de produção ou da venda de um bem ou serviço. Suponhamos que em uma determinada região, onde uma marca específica de bebidas detém o monopólio da venda de refrigerantes, ou seja, é a 
única a fabricar e a vender o produto, uma mulher com sede queira ingerir uma bebida não alcoólica e gasosa. Ela terá seu poder de escolha limitado, pois só há uma marca, mas permanecerá livre para saciar sua sede bebendo água ou cerveja. Apenas quando sua sede se converte, sem outra opção, na imperativa necessidade de comprar obrigatoriamente a bebida aludida, se instaura o monopólio radical (ILLICH, 1985 apud TUNES; PEDROZA, 2011).

Illich (1985 apud TUNES; PEDROZA, 2011) discorre ainda sobre outro âmbito no qual o monopólio radical prevalece: o da mobilidade urbana. Geralmente modeladas para favorecer a circulação de automóveis, as grandes cidades acabam limitando e até extinguindo os meios não motorizados de locomoção, ao que muitos cidadãos se sentem impotentes para se deslocar sem motor. Nota-se que em ambos os setores - produtivo e viário - um mesmo processo opera, o controle exclusivo da produção industrial (que garante a oferta) sobre a satisfação de uma necessidade humana (demanda). Para a demanda nutricional, por exemplo, oferecem-se alimentos industrializados; para a demanda de informação e comunicação, telefone, internet, televisão, rádio etc.; para a locomoção, veículos; para a cura de doenças, fármacos, e assim por diante.

Por fim, a educação, ao se afastar de um modelo livre e espontâneo e se transmudar em um sistema institucionalizado e obrigatório, torna-se um grande monopólio radical. Uma vez estruturada para atender às exigências ocupacionais e operacionais do setor produtivo, a escola consolida, nas décadas subsequentes à Revolução Industrial, até a atualidade, seu estreito ajustamento com ele. Tempo de escolaridade e desempenho acadêmico tornamse, portanto, indicadores de competência laboral, fornecendo, por um lado, para as corporações, subsídios para processos de seleção e contratação e, por outro, para os estudantes, melhores ou piores perspectivas de futuro profissional. Dada a crescente e generalizada exigência de comprovada escolarização para a ocupação de inúmeros postos de trabalho, a escola se firma como condição sine qua non para a realização do sonho do bom emprego (ILLICH, 1985).

Contudo, Tunes e Pedroza (2011) alertam para o potencial excludente do monopólio radical escolar, uma vez que o indivíduo que não frequentou a escola ou não obteve sucesso em sua jornada acadêmica vê reduzidas suas chances de inserção no mundo do trabalho. De acordo com as autoras, não frequentar a escola seria como inexistir socialmente e, como ela é obrigatória, não frequentá-la também significa estar fora da lei. Estar fora da escola implica ainda, o entendimento de muitos teóricos e juristas dos séculos XX e XXI, 
corroborados pelos estudos recentes citados no início deste texto, em uma maior vulnerabilidade à adesão à criminalidade. Frequentá-la e envolver-se em suas atividades, por outro lado, corresponderiam a medidas tanto preventivas quanto corretivas da delinquência juvenil, o que reitera a tendência no tratamento educacional desse fenômeno, discutida na primeira parte do artigo.

Anton Makarenko (1986 apud ZANELLA, 2011, p. 127), um dos pioneiros em nível internacional na educação de adolescentes infratores, já no início do século passado, afirmava a grande relevância da escola: "Nos últimos anos apoiei-me firmemente na escola [...] e estou completamente convencido de que a verdadeira reeducação, a reeducação total, a que exclua reincidências, só é possível através da escola do ensino secundário". Esse pensamento ilustra uma onda internacional que atingiu o Brasil, influenciando a letra das leis que têm prescrito medidas para indivíduos menores de 18 anos que praticaram infrações.

Inicialmente, o primeiro Código de Menores (BRASIL, 1927, Artigo 102) deliberou: "a autoridade competente poderá autorizar o trabalho $[. .$.$] comtanto que recebem a instrucção escolar, que lhes seja$ possível". Posteriormente, o segundo Código de Menores (BRASIL, 1979, Artigo $9^{\circ}, \$ 2^{\circ}$ ) endossou: “a escolarização e a profissionalização do menor serão obrigatórias". E, finalmente, o Estatuto da Criança e do Adolescente (ECA) (BRASIL, 1990, Artigo 120, \ $1^{\circ}$ ) ratificou: "são obrigatórias a escolarização e a profissionalização".

O ECA estipula seis medidas socioeducativas a serem aplicadas a pessoas entre 12 e 18 anos que cometeram ato infracional: (i) advertência, (ii) obrigação de reparar o dano, (iii) prestação de serviços à comunidade, (iv) liberdade assistida, (v) semiliberdade e (vi) internação (BRASIL, 1990). As duas primeiras são breves, não impactando significativamente a vida escolar do adolescente. No caso da terceira medida, porém, o Estatuto define que a realização das atividades não deve prejudicar a frequência à escola. Para a quarta medida, o ECA designa uma pessoa para acompanhar o socioeducando, a qual deve supervisionar sua frequência e seu aproveitamento escolar e, se necessário, solicitar sua matrícula. $\mathrm{Na}$ quinta medida, ao adolescente é imposta uma restrição apenas parcial de sua liberdade, de forma que parte de seu tempo livre deve ser ocupado pela frequência a uma escola de sua comunidade. Enfim, na sexta medida o educando sofre restrição integral de sua liberdade, permanecendo em uma unidade de internação, dentro da qual comumente funcionam escolas públicas.

Notemos que na sexta medida, o adolescente autor de ato infracional comparece a uma instituição de ensino específica, 
enquanto que nas três penúltimas ele frequenta uma escola regular. A Lei 12.594/12, que instituiu o Sistema Nacional de Atendimento Socioeducativo, torna mais clara essa diferenciação quando determina, no caso da sexta medida, que em toda unidade de internação deve haver um espaço com salas de aulas e salas para secretaria e direção escolar e, no tocante às três penúltimas, que as instituições devem estreitar relações com as escolas que recebem o adolescente. Esse preceito reflete o paradigma da incompletude institucional, segundo o qual a política de aplicação das medidas socioeducativas não é suficiente para garantir todos os direitos do adolescente, devendo, portanto, articular-se com outros serviços que visem atender a esses direitos, tais como a escola (BRASIL, 2006; 2012).

Cabe, agora, analisar a conjuntura do século XXI, quando já foram metabolizadas as influências históricas aqui debatidas. Temos o sujeito (socioeducando), numa fase propícia à aprendizagem e à mudança de conduta (adolescência), razão para educá-lo (qualificação para o trabalho) e a esperança de que essa educação poderá afastá-lo da criminalidade, correlata à ideia de que longe do ensino o adolescente fica mais vulnerável ao crime. Temos um espaço oficial onde esse ensino ocorrerá (escola), afora a previsão legal de sua frequência obrigatória. Escolas regulares devem acolher adolescentes que cumprem medida socioeducativa em meio aberto, fornecendo-lhes condições pedagógicas para o seu pleno desenvolvimento cidadão. Ora, que fatores obstaculizam a aceitação do adolescente autor de ato infracional na escola?

\section{A ESCOLA À SOMBRA DA DESIGUALDADE: JOVENS POBRES EM DESVANTAGEM ESCOLAR E LABORAL}

Um passo importante na solução dessa incógnita é o exame da evolução histórica da escola brasileira, prestando particular atenção ao perfil da clientela por ela atendida ao longo do tempo. Queiroga (2005) salienta que a educação escolar no Brasil permaneceu por muito tempo reservada às elites. Porém, o desenvolvimento industrial na Primeira República exigia um número progressivamente maior de quadros técnicos e científicos, acarretando em mudanças estruturais na escola. De acordo com Harper et al. (1987), surgia a necessidade de instruir a massa proletária que se aglomerava nos grandes centros urbanos, dotando-lhes de um mínimo de cultura e competência necessárias à sua integração na sociedade industrial.

Iniciava-se, então, em solo brasileiro, nas primeiras décadas do século XX, um amplo movimento favorável à universalização do 
acesso à escola, não sem o franco apoio da classe operária, que via na educação escolar um passaporte para a emancipação de seus filhos, que assim poderiam usufruir de inéditas oportunidades de ascensão social (HARPER et al., 1987). Cada vez mais simpáticas aos governantes, para os quais a educação seria a mola propulsora do progresso do país, as reivindicações pró-democratização do ensino foram sendo atendidas no decorrer do século XX e início do XXI, quando se assiste a uma redução do número de crianças e adolescentes fora da escola e a uma ampliação de vagas no sistema público de educação, a qual, finalmente, foi consagrada como direito universal na Constituição de 1988.

Para Harper et al. (1987), entretanto, as meras inserção e permanência no sistema formal de ensino não implica sua democratização, pois alunos provenientes de estratos socioculturais diferentes não dispõem das mesmas chances de êxito acadêmico. Isso porque, prosseguem os autores, a escola, de forma geral, está histórica e estruturalmente alinhada com a cultura das classes mais favorecidas, por ela comumente adotada, legitimada e perpetuada. Dessa forma, os alunos de classes abastadas, mais familiarizados com a linguagem imposta e exigida pela escola, experienciariam com menos frequência a sensação de que a escola é um mundo sem conexão com sua realidade, ao passo que os estudantes dos meios populares poderiam estranhar a linguagem, as normas e os valores tradicionalmente difundidos pela instituição escolar como corretos.

Com a entrada das classes populares na escola, os educadores foram confrontados com um novo perfil de alunos, com outras culturas, experiências de vida e práticas sociais, elementos que até então não faziam parte do cotidiano escolar. Todavia, não houve uma séria preocupação em torno da atualização das práticas e estruturas pedagógicas tendo em vista o novo público que agora compunha o corpo discente, as quais permaneceram afinadas com um perfil que cada vez mais se afastava da escola pública, ocupando as instituições privadas. Ao não conceder importância à diferença como um dado humano e cultural e ao não se predispor a dialogar com ela - pelo contrário, elegendo um padrão como válido e rechaçando os demais grande parte dos agentes da escola acabaram fazendo desta um espaço de reprodução das desigualdades sociais (ILLICH, 1985; PATTO, 1996; LIRA, 2008; DIAS; ONOFRE, 2010; CAMPOLINA; MARTÍNEZ, 2011; FERREIRA, 2011; FRANZOI, 2011; LEÃO, 2011).

Para Paulo Freire (1992), essa típica distância, por parte da escola, das possibilidades educacionais dos alunos de origem popular foi uma das principais responsáveis pelo fracasso de vários projetos pedagógicos, e o resultado pífio se repetirá em qualquer outra experiência educativa 
que não leve em conta a realidade dos indivíduos a quem se destina. Tal fracasso escolar, pelo qual usualmente os próprios estudantes são culpabilizados, se traduz em fenômenos como ausência de interesse pelas atividades escolares, indisciplina, notas baixas, repetência, distorção idade-série e evasão escolar, majoritariamente notados na trajetória educacional de alunos oriundos das camadas populares (HARPER et al., 1987; PATTO, 1996; SILVA, 2009; UNICEF, 2009; RODRIGUES; CRUZ, 2010; FERREIRA, 2011).

A desconexão entre a realidade social dessa clientela específica e os conteúdos e parâmetros escolares é apontada por alguns autores como uma das principais razões para o baixo rendimento e o insucesso acadêmico de alunos de berço popular. Por não perceberem sentido ou utilidade nas temáticas trabalhadas na escola, por vezes artificiais e enfadonhas, e não vislumbrarem na instituição possibilidades de concretização de suas aspirações e necessidades, nem se sentirem à vontade para trazer para esse espaço sua maneira de falar e suas vivências sociais e comunitárias, muitos educandos concluem que não vale a pena estar na escola ou se dedicar às suas atividades, pois a instituição não fará muita diferença em suas vidas (HARPER et al., 1987; SILVA, 2009). Desse modo, duas vias se perspectivam, permanecer na escola, mas sem motivação para os estudos e, portanto, com desempenho aquém do esperado, ou abandoná-la definitivamente. Esta última, conforme Patto (1996 apud SILVA, 2009, p. 39), é o resultado de uma dupla rejeição: "a escola não aceita os alunos do jeito que eles são, e os alunos, por sua vez, não aceitam a escola como é. Resultado: evasão".

Acrescente-se a isso o fato de muitas escolas serem obsoletas e resistentes a mudanças. Quando a instituição educacional, na contramão do que se tem frequentemente observado no panorama escolar contemporâneo, não acompanha os avanços sociais e tecnológicos de sua época e não lança mão de instrumentos pedagógicos atrativos, estimulantes e sincronizados com as tendências atuais, torna-se uma tarefa praticamente impossível evitar o desinteresse e a desmotivação de um alunado jovem e moderno (HARPER et al., 1987; ADORNO, 1993 apud DIAS; ONOFRE, 2010; FUCHS, 2009; UNICEF, 2009). Não obstante, muitas vezes os educadores responsabilizam individualmente os estudantes por sua desimplicação, alegando serem estes portadores de uma espécie de repulsa antiescolar característica de uma juvenilidade rebelde e desafiadora, raciocínio simplista que acaba ocultando os possíveis condicionantes institucionais do fenômeno (TEIXEIRA, 2008; LEÃO, 2011).

O provável principal motivo pelo qual boa parte da população juvenil de procedência popular prossegue seus estudos escolares, 
afora a obrigatoriedade prevista em lei para o Ensino Fundamental, é a generalizada exigência das credenciais escolares pelos mais diversos domínios do universo do trabalho, decorrente da ascensão da escola à condição de monopólio radical. Por essa razão, a interface entre organização escolar e juventude pobre pode ter sua descompassada fisionomia atenuada, afastando-se do patamar do nonsense e inscrevendo-se no registro do paradoxo, sobre o qual discorre Sposito (2008 apud FRANZOI, 2011, p. 124):

[...] há um paradoxo já no início da expansão recente do acesso à escola sob o ponto de vista dos jovens: de um lado o forte reconhecimento de que a escolaridade é fundamental e, ao mesmo tempo, a ausência de sentido imediato para essa escola. Ocorre uma espécie de dialética entre o sentido possível do projeto escolar que se volta para o futuro e a ausência de sentido do tempo escolar presente.

A estável expectativa por um emprego digno no futuro e a forte convicção de que o atravessamento do itinerário escolar é o caminho mais seguro e prudente até sua consecução impulsionam o estudante a continuar seu labor formativo, bem como a suportar e relativizar o pouco sentido do maçante aqui-agora pedagógico, tormento que teria cada minuto de duração compensado por uma estabilidade financeira futura. No entanto, na vida real, os fatos nem sempre se sucedem como reza tal script, pois é justamente na seara laboral que a desigualdade social, autenticada e perpetuada pela escola, despeja seu mais lesivo fluxo de reverberações.

Synders (1981 apud CRUZ, 2010, p. 158) afirma que "o sistema de ensino retraduz continuamente as desigualdades de nível social por desigualdades de nível escolar". Complementando o raciocínio do autor, estas se transmudam em desigualdades de nível ocupacional e remuneratório. Isto é, como a entrada no mercado de trabalho é em função do êxito acadêmico, e este, por sua vez, tende a ser mais vivenciado pelos alunos pertencentes às classes média e alta, com cuja cultura a escola está historicamente equalizada, enquanto os estudantes de origem popular, estrangeiros em uma instituição que não fala sua língua, propendem mais ao desinteresse e ao insucesso escolar, aquele grupo de educandos muito provavelmente terá melhores condições de inserção laboral que estes.

A história tem testemunhado a preponderante ocupação, pelas classes abastadas, dos mais elevados postos de trabalho em várias civilizações, não sem antes terem acesso também privilegiado - e, por vezes, exclusivo - às melhores oportunidades formativas (HARPER et al., 1987; FERREIRA, 2011). A duradoura presença majoritária dessas categorias sociais nos centros de ensino superior, 
inclusive por estarem em melhores condições de serem aprovados nos processos seletivos, é um dado histórico determinante para essa vantagem social, visto que grande parte dos melhores cargos de trabalho requisita formação de nível superior. A despeito das ações afirmativas recentemente implementadas no setor educacional brasileiro, as quais contribuíram decisivamente para a amenização dessa desigualdade, ao fomentar o franco ingresso da população negra e pobre em universidades públicas e privadas, indivíduos negros e de origem popular continuam exercendo as profissões menos valorizadas, ocupando os cargos menos prestigiosos e, por conseguinte, recebendo os salários mais modestos.

Ademais, o embaraço dessa parcela da população com a questão trabalhista ganhou contornos agravantes nas últimas décadas, quando se assiste a um amplo processo de precarização das condições de trabalho e de elevação dos índices de subemprego e desemprego, consequências da sistemática implantação de políticas neoliberais a nível internacional (BLANCH, 2014). O discurso de um dos participantes do estudo de Castro e Abramovay (2002, p. 154) ilustra nitidamente a gravidade do problema: "Falta emprego para quem tem escolaridade ou não. Tem gente por aí formado, e não consegue emprego". Na medida em que o desemprego também atinge aqueles que possuem as credenciais escolares requeridas pelo mercado de trabalho, a dificuldade de o indivíduo com pouca escolaridade em encontrar uma vaga fica ainda maior, pois mesmo que ambicione um cargo com menos status, terá que disputá-lo com um concorrente escolarizado, que se encontrará em clara vantagem.

Nessa conjuntura, o futuro profissional e as consequentes emancipação e estabilidade financeiras teoricamente garantidas aos concluintes do percurso escolar tornam-se aspectos cada vez mais incertos. Leão (2011, p. 110) acentua que os adolescentes são impelidos a estudar "por exigências sociais (reconhecimento social, acesso a alguns postos de trabalho etc.), mas sabendo de antemão que o retorno do seu investimento em termos de mobilidade social não está garantido. Estudar é uma necessidade, mas não uma garantia”.

Face a essa implacável realidade, oportunidades ilícitas de trabalho e remuneração, tais como o tráfico de drogas, se impõem como alternativas amiúde sedutoras, especialmente para os adolescentes que não frequentam a escola ou que possuem acentuada distorção idade-série. Cientes da precariedade de sua situação perante o mercado formal de trabalho, desejosos em comprar e usufruir os bens e produtos expostos nas vitrines do consumo, ávidos por se tornarem financeiramente independentes de 
seus pais e constatantes da perdurável e aparentemente insuperável condição de pobreza e vulnerabilidade de seus vizinhos e parentes da mesma condição social que optaram pelo trabalho legal, alguns adolescentes das periferias urbanas encontram no crime uma chance de mudar de vida (CASTRO; ABRAMOVAY, 2002).

Eis um ponto de exemplificação, por um lado, do resultado comum dos estudos mencionados no início deste artigo, que situam o atraso e o abandono escolar como preditores da delituosidade precoce, e, por outro, do espírito das leis que dispõem sobre o atendimento a adolescentes infratores, unânimes defensoras da centralidade da escolarização nesta política. Se, como ilustram Castro e Abramovay (2002), a distância entre a não escolarização adequada e a criminalidade juvenil se encurta à medida que o adolescente tem reduzidas suas perspectivas de inserção no mercado de trabalho legal, por não dispor das credenciais escolares por este exigidas, as medidas socioeducativas extraem boa parte de sua pertinência da tentativa de promover a aquisição dessas credenciais através da educação escolar. Espera-se que, ao final da medida e do percurso escolarizante por esta fomentado, o adolescente infrator esteja em condições de encontrar meios lícitos de autossustento, distanciando-se das veredas delituosas de remuneração, a exemplo do narcotráfico. Resta, agora, entender por que a instituição responsável por essa tarefa apresenta relutância em aceitar o adolescente.

\section{0 "DESLUGAR" DO ADOLESCENTE INFRATOR NA ESCOLA: RESISTÊNCIA, REPULSA E RECUSA}

Antes de debater os percalços da jornada escolar de adolescentes que cumprem medida socioeducativa em meio aberto, é conveniente empreender uma caracterização desse público. Em linhas gerais, a maioria é formada por jovens do sexo masculino, com idades entre 15 e 18 anos, afrodescendentes, pertencentes a famílias de baixa renda, em sua maioria monoparentais, cujos membros têm baixa escolaridade e encontram-se ou desempregados ou desempenhando funções mal remuneradas, e moradores de zonas urbanas periféricas, não raro localizadas em áreas de risco social (ASSIS, 1999; TOREZAN, 2005; BRASIL, 2006; FUCHS, 2009; CRUZ, 2010; OLIVEIRA, 2010; PAULA, 2011).

É relevante frisar que esse retrato não contempla toda a população infratora juvenil, que também é composta por indivíduos pertencentes às classes privilegiadas, mas apenas a parcela que, dentre os praticantes de infração, é apreendida, autuada e submetida ao cumprimento de medida socioeducativa. Tal descompasso denuncia 
o vergonhoso quadro de seletividade do sistema de justiça, que há décadas perdura inequacionado, sujeitando a população pobre a um tratamento jurídico-penal mais rigoroso do que o dos integrantes dos demais estratos sociais (FOUCAULT, 1987).

Mais lamentável ainda é perceber que as vítimas da seletividade do sistema de justiça também figuram entre os excluídos do monopólio radical escolar, sobre os quais discorremos na terceira parte do artigo. À luz dos dados supracitados, pode-se inferir que a maioria dos socioeducandos compartilha com os demais membros de sua classe social uma posição de desconforto no panorama escolar, tradicionalmente desalinhado com sua realidade cultural.

Tal conjectura possui amplo respaldo bibliográfico. Assis (1999), Brasil (2006), Gallo e Williams (2008), Unicef (2009), Dias e Onofre (2010), Rodrigues e Cruz (2010), Zanella (2010) e Oliveira (2011) ressaltam que fenômenos como ausência de atração pela escola, notas baixas, altas taxas de reprovação, distorção idade-série, analfabetismo funcional e interrupção voluntária dos estudos escolares são bastante frequentes na trajetória de vida de adolescentes autores de infração. Silva (2009), por sua vez, revela em seu estudo a transgeracionalidade desses processos, porquanto constata que a maioria das mães e dos pais desses adolescentes não concluiu o Ensino Fundamental, sendo que alguns deles nem sequer chegaram a ir à escola.

Queiroz (1984 apud MARTINS et al., 2005) e Pereira e Sudbrack (2009 apud ZANELLA, 2010) enfatizam as sensações de não pertencimento à instituição escolar e de não reconhecimento de suas potencialidades humanas vivenciadas pelos adolescentes, muitos dos quais, acresce Silva (2009, p. 83), "não conseguem ver na escola uma ferramenta que possibilite novas perspectivas em relação à sua situação econômica". Dias (2011) destaca as constantes transferências de escola vividas pelos adolescentes, ao que Gallo e Williams $(2005$; 2008) delatam as sistemáticas expulsões enfrentadas por esse público no sistema educacional. Enfim, Castro e Abramovay (2002) sublinham as dificuldades desses adolescentes na busca pelo primeiro emprego, os quais se queixam por não possuírem os níveis de escolaridade e o tempo de experiência tipicamente requisitados, razões pelas quais alguns, assinala Paula (2011), acabam recorrendo aos mercados de trabalho informal e ilegal.

Trata-se de experiências partilhadas com muitos dos demais estudantes de berço popular. Todavia, advertem Adorno (1993 apud DIAS; ONOFRE, 2010) e Rodrigues e Cruz (2010), nem todos os alunos que passam por episódios de insucesso escolar virão a delinquir. Pelo contrário, a juventude infratora é uma minoria da população em idade 
escolar, assim como sua franja pauperizada é uma minoria da juventude pobre. Essa observação é essencial para afastar qualquer possibilidade de confusão com concepções deterministas. Estamos tratando de fatores que contribuem para a adesão de alguns poucos adolescentes ao mundo do crime, jamais a determinando linear ou unicamente. Lidamos, até aqui, com contratempos que são comumente experimentados por estudantes de origem popular na escola; socioeducandos ou não. Examinemos, agora, os problemas vivenciados especialmente por estes.

\section{(i) Ausência de preparação do corpo docente para atender ao socioeducando}

Um grande entrave ao efetivo acolhimento escolar do adolescente em cumprimento de medida socioeducativa é a falta de capacitação prévia, pelos profissionais de educação, para atender a esse público, circunstância verificada na grande maioria das escolas. Muitos educadores desconhecem o texto legal do Estatuto da Criança e do Adolescente, não entendem que o socioeducando tem o direito à educação formal assegurado pelo Estado e apresentam dificuldade em conceber a escola como uma das instituições que compõem o sistema integrado de garantia dos direitos do adolescente autor de ato infracional. Possuem poucas informações acerca dessa política e sobre o seu papel na sua operacionalização (ARONE, 2006; GALLO; WILLIAMS, 2008; FUCHS, 2009; UNICEF, 2009; ZANELLA, 2010).

A essa vicissitude se somam os infortúnios tradicionais do cotidiano educacional, tais como salas de aula lotadas, em condições precárias e incompatíveis com o desenvolvimento do fazer pedagógico; péssimas condições, pouca valorização e baixa remuneração do trabalho docente; escassez e inadequação de espaços e materiais pedagógicos, entre outros (MARTINS et al., 2005; GALLO; WILLIAMS, 2008; TEIXEIRA, 2008; FRANZOI, 2011). Nesse cenário, a ação educativa, já desafiadora e laboriosa, se torna ainda mais árdua com a chegada do socioeducando, requerendo do professor algumas habilidades que ele não desenvolveu em sua formação inicial, e para cuja concretização inexistem condições objetivas e subjetivas.

\section{(ii) A relação professor-socioeducando entre o medo, a discriminação e a rejeição}

Dentre os estilos de interação entre os professores e os adolescentes em cumprimento de medida socioeducativa, dois padrões se notabilizam. No primeiro, mais intimista, o docente sente medo do educando, temor associado a uma insegurança com 
sua chegada à escola e a uma evitação do contato com ele em sala de aula. Cautelosos, esses educadores se sentem intimidados pelos adolescentes (TEIXEIRA, 2008; UNICEF, 2009; ZANELLA, 2010).

O segundo, por outro lado, é caracterizado por posturas mais enérgicas e ríspidas dos docentes para com os socioeducandos, que se sentem discriminados, segregados, agredidos, ameaçados, perseguidos, humilhados, ofendidos e alvos de olhares preconceituosos e tratamento diferenciado, não só pelo ato infracional cometido, que sofre constantes referências, mas também por sua aparência física, pela forma como se vestem, por virem da periferia e por serem negros. Além disso, costumam ser rotulados de agressivos, favelados, problemáticos, infratores e outros estereótipos estigmatizantes (ASSIS, 1999; GALLO; WILLIAMS, 2005; TOREZAN, 2005; SILVA, 2009; UNICEF, 2009; ZANELLA, 2010; DIAS, 2011). Estes, apontam Martins et al. (2005), atingem inclusive a família do adolescente, não raro tachada de desestruturada, problemática e negligente na imposição de limites.

Os efeitos nocivos desses estigmas são bastante duradouros, alcançando ainda os egressos do sistema socioeducativo, os quais, mesmo tendo concluído sua medida e quitado sua dívida com a sociedade, também são vítimas do preconceito e da rejeição da escola. De acordo com Zanella (2010), esses adolescentes não são bemvindos à escola nem antes, nem durante, tampouco posteriormente ao cumprimento da medida. Não obstante, é válido salientar que a escola não é precursora desses processos de hostilização e discriminação, e sim percursora. Isto é, na comunidade escolar são reproduzidas as representações sociais e atitudes sobre o adolescente infrator que circulam previamente na sociedade (TEIXEIRA, 2008). A escola, "infelizmente, e na maior parte das vezes, responde, lida e olha para esses meninos da mesma forma que a sociedade geral: com medo, com preconceito" (UNICEF, 2009, p. 52).

\section{(iii) A recusa do adolescente pela escola e a matrícula por via judicial}

Uma das consequências mais graves da generalizada repulsa da escola ao adolescente em conflito com a lei é a recusa, por parte das autoridades da instituição, em matricular o adolescente e garantirlhe um lugar com os demais estudantes. A alegação mais utilizada é a da ausência de vagas, mas justificativas como a preocupação com a segurança dos outros alunos e com o risco que a presença do socioeducando oferece à dinâmica escolar também são empregadas (GALLO; WILLIAMS, 2008; PAULA, 2010; ZANELLA, 2010). A idade do adolescente também pode dificultar sua inclusão escolar, pois 
ou ele está aquém da faixa etária legalmente estipulada para entrar na modalidade Educação de Jovens e Adultos ou sua idade é muito elevada para a inserção no ensino regular, haja vista a saliente defasagem idade-série apresentada por muitos. Essa situação foi trazida por um coordenador pedagógico entrevistado por Fuchs (2009, p. 207): “eu não posso colocar o menino de 14 anos que tem uma história de vida conturbada numa sala de primeira série, com meninos de 7 anos".

Paula (2010) acrescenta que a dificuldade em conseguir uma vaga no sistema escolar é vivenciada com angústia pelos adolescentes, os quais supõem que a não frequência escolar será vista negativamente pelo juiz, o que poderia culminar no protelamento da medida. Teixeira (2008), por sua vez, menciona em seu estudo que algumas mães de socioeducandos tentam omitir a informação de que seus filhos cumprem medida socioeducativa, na esperança de evitar mais uma negação de vaga. Quando os esforços dos familiares do adolescente e dos profissionais dos programas de medidas socioeducativas se esgotam ou se mostram vãos, estes atores costumam acionar a Promotoria Pública para obrigar judicialmente a escola a efetivar a matrícula (FUCHS, 2009; UNICEF, 2009; ZANELLA, 2010).

\section{(iv) Desincumbência docente e terceirização da resolução de conflitos}

Malogrados em sua tentativa de vetar o ingresso de adolescentes em cumprimento de medida socioeducativa na escola, alguns educadores encontram uma alternativa para evitar o contato com o educando, ao menos nas situações mais críticas: a transferência da responsabilidade da resolução de conflitos para instâncias extraescolares. Diante de episódios de indisciplina e conflitos interpessoais envolvendo os socioeducandos, os professores, sentindo-se intimidados, impotentes e incapazes de interferir, habitualmente convocam instâncias como a polícia militar para solucionar os transtornos, o que confirma a tendência de judicialização das questões escolares na atualidade (UNICEF, 2009; ZANELLA, 2010).

O pesquisador Júlio Groppa Aquino (1998, p. 8-9) tece formidáveis ponderações acerca do emergente ímpeto terceirizante da organização escolar face ao problema da violência:

[...] a escola e seus atores constitutivos, principalmente o professor, parecem tornarse reféns de sobredeterminações que em muito lhes ultrapassam, restando-lhes apenas um misto de resignação, desconforto e, inevitavelmente, desincumbência perante os efeitos de violência no cotidiano prático, posto que a gênese do fenômeno e, por extensão, seu manejo teórico-metodológico residiriam fora, ou para além, dos muros escolares. [...] educadores quase sempre acabam padecendo de uma espécie de sentimento de "mãos atadas" quando confrontados com situações atípicas em 
relação ao plácido ideário pedagógico. Entretanto, o cotidiano escolar é pródigo em eventos alheios a esse ideário-padrão. E os efeitos da violência representam, sem dúvida, a parcela mais onerosa de tais vicissitudes.

\section{A TENSÃO ENTRE A ESCOLA E O ADOLESCENTE INFRATOR: CONSIDERAÇÕES CONCLUSIVAS E PROPOSITIVAS}

Finalizado nosso perscrutamento da trama histórica que confere sentido à intrincada relação entre escola e adolescentes infratores, tornase oportuno escandir os quatro estágios que configuram o percurso escolar típico desses sujeitos. O primeiro estágio é caracterizado pela obrigação da frequência escolar por todas as crianças e adolescentes, que devem ser qualificados para o mundo de trabalho, o qual exigirá dela comprovantes de competência laboral. O segundo é marcado pelo desconforto dos alunos de origem popular, na minoria dos quais incluem-se a maioria dos futuros socioeducandos, com a escola, geralmente dessintonizada com sua realidade cultural, o que favorece $o$ desinteresse e o insucesso acadêmico de alguns desses estudantes, que podem inclusive abandonar a instituição, por não se sentirem atraídos, valorizados, estimulados e motivados para continuar frequentando-a. Vale frisar que muitos adolescentes infratores costumam encontrar-se evadidos da escola quando são apreendidos.

No terceiro estágio, o adolescente, autuado por ato infracional e submetido a uma medida socioeducativa em meio aberto, é obrigado a frequentar uma escola pública regular, onde vivencia experiências de rejeição, hostilidade e segregação ainda mais intensas que aquelas que haviam motivado seu afastamento da escola anterior. Tais episódios também costumam acontecer no quarto e derradeiro estágio, vivido exclusivamente por adolescentes egressos do sistema socioeducativo, que já encerram a medida e cuja frequência escolar não se encontra mais sob a égide da imposição ou supervisão judiciais, mas que continuam enfrentando preconceito e discriminação devido a seu histórico infracional e socioeducativo.

O que essa prototípica sequência de fatos insinua é que a mesma entidade responsável por incluir e acolher o adolescente em conflito com a lei, assegurando-lhe o direito à educação, por via de regra o rejeita, o oprime, o discrimina e o hostiliza, referendando, quando seria um dever ético subverter, a repugnância da população em geral em relação a ele. Há, portanto, um fracasso por parte da escola, que age no avesso de sua função oficial, paradoxo não muito diferente da histórica e cotidiana tentativa de educar estudantes de classe popular descuidando das vivências sociais, culturais e comunitárias que lhes são características. 
A raiz de tal paradoxo provavelmente corresponde, de um lado, ao estatuto de uniformidade e ao ímpeto homogeneizante e padronizador da estrutura escolar, e, de outro, ao seu excessivo conservadorismo e sua alta resistência a mudanças. Dessa forma, a escola, de uma maneira geral, não é apenas uma consagrada zeladora da norma, mas também uma ávida repulsora da diferença. Uma vez que tal diferença remete às desigualdades sociais, podemos conjecturar que da soberania elitista que por um longo período manteve a educação formal um privilégio das classes abastadas, restaram resquícios que, desde o início da universalização do acesso à escola pública até os dias atuais, vêm nutrindo uma aversão às classes populares.

Patto (1992) denuncia a histórica representação pejorativa dessa classe social no reduto escolar, onde tem sido considerada por muitos uma subcultura ignorante, inculta e atrasada. Daí porque os socioeducandos, maciçamente provenientes desse meio e correspondendo a uma ilustração amplificada desse protótipo, sejam alvo privilegiado dos preconceitos, estigmas e estereótipos comumente atribuídos a jovens oriundos de estratos sociais pauperizados, cujo impacto se estende à seara escolar, reverberando nas posturas dos educadores; da tentativa de impedir sua matrícula na escola ao tratamento hostil e segregador a eles dispensado.

A típica inamistosidade da escola para com o adolescente em conflito com a lei é um dos desdobramentos da histórica recusa da instituição em acolher a diversidade sociocultural que tem nas camadas populares suas principais porta-vozes. Tal acolhimento não é sinônimo da mera inserção do adolescente na escola, muitas vezes a duras penas conquistada. Embora importante, a matrícula não é suficiente para garantir ao adolescente o pleno exercício do seu direito à educação, podendo, pelo contrário, agregar novos abalos à sua já debilitada situação social, de modo a tornar sua estadia na escola um fato insustentável e insuportável.

Para a atenuação e a reversão desse quadro alarmante, algumas medidas insinuam-se fundamentais. Em primeiro lugar, a escola precisa se tornar um espaço de generoso acolhimento dos adolescentes de baixa renda, que devem ter seu arcabouço cultural legitimado, o conhecimento que trazem de suas comunidades valorizado, como postula Franzoi (2011), e suas vozes e vivências potencializadas, conforme advoga Leão (2011). Freire (1992) esclarece, no entanto, que partir do nível de leitura de mundo dos educandos não significa se acomodar a ele ou girar em torno dele, mas sim tomá-lo como ponto de partida em uma dinâmica progressiva de construção, amadurecimento e refinamento 
de conhecimentos, que desembocará na apropriação emancipadora dos patamares mais elevados do saber formal. Estes, como sabemos, são essenciais para o empoderamento do indivíduo no universo laboral.

Aos profissionais de educação, por sua vez, devem ser proporcionados dispositivos de formação prévia e continuada para a discussão crítica de temas concernentes aos direitos da criança e do adolescente, ao sistema de justiça juvenil, à criminalidade precoce etc., bem como para o compartilhamento de ideias e experiências e a realização de estudos de caso. Momentos para uma acolhida e uma escuta qualificadas das angústias e dos transtornos gerados pelo cotidiano escolar também precisam ser oportunizados aos docentes, que devem inclusive receber suporte e acompanhamento dos programas de atendimento socioeducativo. Melhores condições laborais e salariais também podem ter um impacto positivo.

Uma vez que a magnitude do problema não se esgota no campo educativo, a eficaz implementação de ações afirmativas de combate às vulnerabilidades e desigualdades sociais e de políticas públicas de inclusão social, promoção da cidadania e garantia de direitos se impõe como uma dimensão medular da atenção ao adolescente. Tal caminho passa obrigatoriamente por medidas estatais de estímulo e apoio à empregabilidade juvenil, tais como as sugeridas por Blanch (2014): facilitação da transição do sistema educacional para o mercado de trabalho, melhoria da qualidade do ensino profissionalizante, correlata à ampliação de vagas, incentivo a empresas para a contratação de jovens etc. Essas medidas devem priorizar os grupos sociais com histórica dificuldade de inserção profissional, a exemplo de jovens de baixa renda moradores de regiões periféricas e egressos do sistema socioeducativo. Segundo Teixeira (2008), ao fornecer ao adolescente boas oportunidades de trabalho e renda, faz-se uma vigorosa oposição ao crime e ao narcotráfico, que avidamente o disputam.

Embora sob um prisma realista sejamos levados a reconhecer a longa distância da qual nos encontramos do cenário até aqui idealizado, também não seria sensato de nossa parte sucumbirmos a uma posição fatalista que homologasse sua inalcançabilidade. Talvez singelos passos iniciais, modestos esforços preliminares de profissionais que se lancem ousadamente a experimentações micropolíticas sejam necessários para preparar o caminho para mudanças futuras em nível macroestrutural. Não se trata de uma convocação a um apoliticismo abortador da cobrança por iniciativas das autoridades públicas, a qual deve continuar ocorrendo, mesmo após as conquistas, mas sim de um apelo à ação enquanto estas não se concretizam, intervalo de tempo 
no qual muitos adolescentes precisarão de apoio e consideração. A propósito dos riscos dessa empreitada, despeçamo-nos com Freire (1992, p. 41): "Não é possível viver, muito menos existir, sem riscos. O fundamental é nos prepararmos para saber corrê-los bem".

\section{REFERÊNCIAS}

AQUINO, Júlio Groppa. A violência escolar e a crise da autoridade docente. Cadernos Cedes, Campinas, v. 19, n. 47, p. 7-19, dez. 1998.

ARIÈS, Philipp. História social da criança e da família. Rio de Janeiro: LTC, 1981.

ARONE, Mariangélica. Sentidos e significados da escola para o adolescente em semiliberdade. 2006. 171 f. Dissertação (Mestrado em Educação) - Pontifícia Universidade Católica de São Paulo, São Paulo, 2006.

ASSIS, Simone Gonçalves de. Traçando caminhos em uma sociedade violenta: a vida de jovens infratores e de seus irmãos não-infratores. Rio de Janeiro: FIOCRUZ, 1999.

BLANCH, Josep M. La juventud NINI, un agujero negro psicosocial. Revista Psicologia: Organizações e Trabalho, Brasília, v. 14, n. 4, p. 355-366, out./dez. 2014.

BRASIL. Constituição da República Federativa do Brasil. 1988. Disponível em: <http://www. planalto.gov.br/ccivil_03/constituicao/Constituicao.htm>. Acesso em: 24 nov. 2014.

BRASIL. Decreto $n^{\circ}$ 17.943- $A$, de 12 de outubro de 1927. Consolida as leis de assistência e protecção a menores. Disponível em: <http://www2.camara.leg.br/legin/fed/ decret/1920-1929/decreto-17943-a-12-outubro-1927-501820-publicacaooriginal-1-pe. html>. Acesso em: 24 nov. 2014.

BRASIL. Lei no 6.697, de 10 de outubro de 1979. Institui o Código de Menores. Disponível em: <http://www.mp.sp.gov.br/portal/page/portal/cao_infancia_juventude/legislacao_ geral/leg_geral_federal/LEI_6697_79.HTM>. Acesso em: 24 nov. 2014.

BRASIL. Lei $n^{\circ}$ 8.089, de 12 de julho de 1990. Dispõe sobre o Estatuto da Criança e do Adolescente e dá outras providências. Disponível em: <http://bvsms.saude.gov.br/bvs/ publicacoes/estatuto_crianca_adolescente_3ed.pdf>. Acesso em: 24 nov. 2014

BRASIL. Lei $n^{\circ}$ 12.594, de 18 de janeiro de 2012. Sistema Nacional de Atendimento Socioeducativo. Disponível em: < http://www.planalto.gov.br/ccivil_03/_ato20112014/2012/lei/112594.htm>. Acesso em: 24 nov. 2014

BRASIL. Secretaria Especial dos Direitos Humanos. Sistema Nacional de Atendimento Socioeducativo. Brasília: CONANDA, 2006.

CAMPOLINA, Luciana de Oliveira; MARTÍNEZ, Albertina Mitjáns. A escola em sua dimensão reprodutiva: possibilidades e limites de inovação na educação. In: TUNES, Elizabeth (org.). Sem escola, sem documento. Rio de Janeiro: E-papers, 2011. p. 31-58.

CARIDE, José Antonio. Las fronteras de la Pedagogía Social: perspectivas científica e histórica. Barcelona, Espanha: Gedisa, 2004.

CARLOS, Viviani Yoshinaga. Escolas de reforma: um estudo sobre as ideias que sustentaram a sua organização no Brasil. 2013. 144 f. Dissertação (Mestrado em Serviço Social e Política Social) - Universidade Estadual de Londrina, Londrina, 2013.

CASTRO, Mary Garcia; ABRAMOVAY, Miriam. Jovens em situação de pobreza, vulnerabilidades sociais e violências. Cadernos de Pesquisa, São Paulo, n. 116, p. 143-176, jul. 2002. 
CRUZ, Ana Vládia Holanda. O adolescente em conflito com a lei e a escola: criminalização e inclusão perversa. 2010. 302 f. Dissertação (Mestrado em Psicologia) - Universidade Federal do Rio Grande do Norte, Natal, 2010.

DIAS, Aline Fávaro. O jovem autor de ato infracional e a educação escolar: significados, desafios e caminhos para a permanência na escola. 2011. 170 f. Dissertação (Mestrado em Educação) - Universidade Federal de São Carlos, São Carlos, SP, 2011.

DIAS, Aline Fávaro; ONOFRE, Elenice Maria Cammarosano. A relação do jovem em conflito com a lei e a escola. Impulso, Piracicaba, v. 20, n. 49, p. 31-42, jan./jun. 2010.

ESCANDÓN, Celia Blanco. Estudio Histórico y Comparado de la Legislación de Menores Infractores. In: MARTÍN, Nuria González (coord.). Estudios Jurídicos en homenage a Marta Morineau: Tomo II. México: Universidad Nacional Autônoma de México, 2006. p. 83-116.

FERREIRA, Mônica Dias Peregrino. Juventude e escola. In: DAYRELL, Juarez; MOREIRA, Maria Ignez Costa; STENGEL, Márcia (org.). Juventudes contemporâneas: um mosaico de possibilidades. Belo Horizonte: PUC Minas, 2011. p. 81-98.

FOUCAULT, Michel. Vigiar e punir. 20. ed. Petrópolis, RJ: Vozes, 1987.

FRANZOI, Naira Lisboa. Juventude, trabalho e educação: crônica de uma relação infeliz em quatro atos. In: DAYRELL, Juarez; MOREIRA, Maria Ignez Costa; STENGEL, Márcia (org.). Juventudes contemporâneas: um mosaico de possibilidades. Belo Horizonte: PUC Minas, 2011. p. 117-134.

FREIRE, Paulo. Pedagogia da esperança: um reencontro com a pedagogia do oprimido. Rio de Janeiro: Paz e Terra, 1992.

FUCHS, Andréa Márcia Santiago Lohmeyer. Telhado de vidro: as intermitências do atendimento socioeducativo de adolescentes em semiliberdade. 2009. 273 f. Tese (Doutorado em Política Social) - Universidade de Brasília, Brasília, 2009.

GALLO, Alex Eduardo; WILLIAMS, Lúcia Cavalcanti de Albuquerque. Adolescentes em conflito com a lei: uma revisão dos fatores de risco para a conduta infracional. Psicologia: Teoria e Prática, São Paulo, v. 7, n. 1, p. 81-95, 2005.

GALLO, Alex Eduardo; WILLIAMS, Lúcia Cavalcanti de Albuquerque. A escola como fator de proteção à conduta infracional de adolescentes. Cadernos de Pesquisa, São Paulo, v. 38, n. 133, p. 41-59, jan./abr. 2008.

GOMES, Olegário Gurgel Ferreira. Ato infracional, legalidade e consenso: estudo acerca das diretrizes para a justiça juvenil. 2009. 200 f. Dissertação (Mestrado em Ciências Jurídicocriminais) - Universidade de Lisboa, Lisboa, Portugal, 2009.

HARPER, Babette; CECCON, Claudius; OLIVEIRA, Miguel Darcy de; OLIVEIRA, Rosiska Darcy de. Cuidado, escola! - desigualdade, domesticação e algumas saídas. 24. ed. São Paulo: Brasiliense, 1987.

ILLICH, Ivan. Sociedade sem escolas. 7. ed. Petrópolis, RJ: Vozes, 1985.

LEÃO, Geraldo. Entre sonhos e projetos de jovens, a escola. In: DAYRELL, Juarez; MOREIRA, Maria Ignez Costa; STENGEL, Márcia (org.). Juventudes contemporâneas: um mosaico de possibilidades. Belo Horizonte: PUC Minas, 2011. p. 99-116.

LIRA, Geneluza Dias. Fracasso escolar: Visão de Professores nas Séries Iniciais do Ensino Fundamental da Cidade de Cajazeiras PB. 2008. 146 f. Dissertação (Mestrado em Ciências da Educação) - Universidade Lusófona de Humanidades e Tecnologias, Lisboa, Portugal, 2008.

MANACORDA, Mario Alighiero. História da educação: da antiguidade aos nossos dias. 3. ed. São Paulo: Cortez, 1992. 
MARTINS, Jeyse; CATOZZI, Caroline; SAYEGH, Flávia; BARIANI, Isabel Cristina Dib. O professor e o aluno em liberdade assistida: um estudo exploratório. Psicologia escolar e educacional, Campinas, v. 9, n. 1, p. 117-125, jun. 2005.

OLIVEIRA, Elisangela Sobreira de. Escolarização de adolescentes em conflito com a lei: um estudo em Rondônia. 2011. 129 f. Dissertação (Mestrado em Psicologia) - Universidade Federal de Rondônia, Porto Velho, 2011.

OLIVEIRA, Julia Galiza de. A concepção socioeducativa em questão: entre o marco legal e limites estruturais à concretização de direitos do adolescente. 2010. 114 f. Dissertação (Mestrado em Política Social) - Universidade de Brasília, Brasília, 2010.

ONU - Organização das Nações Unidas. Convenção sobre os direitos da criança. 1989. Disponível em: < http://www.unicef.pt/docs/pdf_publicacoes/convencao_direitos_crianca2004.pdf>. Acesso em: 24 nov. 2014.

PATTO, Maria Helena de Souza. A família pobre e a escola pública - anotações sobre um desencontro. Psicologia USP, São Paulo, v. 3, n. 1/2, p. 107-201, 1992.

PATTO, Maria Helena de Souza. A produção do fracasso escolar: histórias de submissão e rebeldia. São Paulo: T. A. Queiroz, 1996.

PAULA, Liana de. Liberdade assistida: punição e cidadania na cidade de São Paulo. 2011. 275 f. Tese (Doutorado em Sociologia) - Universidade de São Paulo, São Paulo, 2011.

QUEIROGA, Maria do Socorro Nóbrega. O discurso do fracasso escolar como tecnologia de governo da infância: arqueologia de um conceito. 2005. 260 f. Tese (Doutorado em Sociologia) Universidade Federal da Paraíba, João Pessoa, 2005.

RODRIGUES, Rosemeri Terezinha Ferreira da Rocha; CRUZ, Gilmar de Carvalho. Da sala à cela: rotas marginais de adolescentes em situação de conflito com a lei. In: XXXIII REUNIÃO ANUAL DA ANPEd. 2010. Anais online. Disponível em: < http://www.anped. org.br/33encontro/app/webroot/files/file/Trabalhos\%20em\%20PDF/GT03-6283--Int. pdf>. Acesso em: 24 nov. 2014.

SILVA, Roberto da. Pedagogia Social: uma profissão para quem faz Educação Popular, social e comunitária no Brasil. 2008. 128 f. Tese (Livre Docência em Educação) - Universidade de São Paulo, São Paulo, 2008.

SILVA, Izabel Cristina Lucas Barreto da. Fracasso escolare adolescentes infratores: a vulnerabilidade social de adolescentes de baixa escolaridade. 2009. 111 f. Dissertação (Mestrado em Educação) - Universidade do Estado do Rio de Janeiro, Rio de Janeiro, 2009.

SOUZA NETO, João Clemente; CENTOLANZA, Carlos Antonio. Da prática do desvio ao protagonismo. Psico, Porto Alegre, v. 41, n. 1, p. 128-136, jan./mar. 2010.

TEIXEIRA, Maria de Lourdes Trassi. Uma relação delicada: a escola e o adolescente em conflito com a lei. 2008. Disponível em: <http://www.promenino.org.br/Ferramentas/ Conteudo/tabid/77/ConteudoId/88cc0cd9-2ae1-42a2-bc8f-31b2f9f1f6d9/Default.aspx>. Acesso em: 24 nov. 2014.

TOREZAN, Sonia Aparecida Bortolotto. Ser jovem em meio à violência: identidade X singularidade no confronto com a lei. 2005. 154 f. Dissertação (Mestrado em Educação) Universidade Estadual de Campinas, Campinas, 2005.

TUNES, Elizabeth; PEDROZA, Lília Pinto. O silêncio ou a profanação do outro. In: TUNES, Elizabeth (org.). Sem escola, sem documento. Rio de Janeiro: E-papers, 2011. p. 15-29.

UNICEF - Fundo das Nações Unidas para a Infância. $O$ direito de aprender: potencializar avanços e reduzir desigualdades. Brasília: Unicef, 2009. 
ZANELLA, Maria Nilvane. Adolescente em conflito com a lei e escola: uma relação possível? Revista Brasileira Adolescência e Conflitualidade, São Paulo, v. 3, p. 4-22, 2010.

ZANELLA, Maria Nilvane. Bases teóricas da Socioeducação: análise das práticas de intervenção e metodologias de atendimento do adolescente em situação de conflito com a lei. 2011. 209 f. Dissertação (Mestrado Profissional Adolescente em Conflito com a Lei) - Universidade Bandeirante de São Paulo, São Paulo, 2011.

\section{NOTAS}

${ }^{1}$ Até 1990, o termo "menor" se referia aos indivíduos com pouca idade que se encontravam em situação de rua, abandono, orfandade, pobreza extrema ou conflito com a lei. As medidas de "proteção" e "assistência" previstas nos Códigos de Menores (BRASIL, 1927; 1979), as quais se resumiam basicamente à reclusão em instituições disciplinares, se direcionavam a toda essa população, e não apenas aos que cometiam delitos. Isso ocorria porque a pobreza era considerada a principal causa da delinquência, de modo que todo menor ou era criminoso ou estava "na iminência de o se tornar". Entendia-se que internar o menor seria a melhor estratégia para protegê-lo do perigo representado pelas "condições degradantes" de suas famílias e salvaguardar a sociedade da "ameaça" que eles representavam. Até então, apenas quem pertencia aos núcleos familiares de classe média e elite eram chamados de "crianças" e "adolescentes" (RIZZINI, 1997 apud OLIVEIRA, 2010). Porém, com a promulgação do Estatuto da Criança e do Adolescente (BRASIL, 1990), aquele termo passou a designar todo cidadão com idade entre zero e doze anos incompletos; este, todo indivíduo de 12 a 18.

Recebido: 15/12/2014

Aprovado: 20/10/2015

Contato:

UFBA - Universidade Federal da Bahia IPS -Instituto de Psicologia Estrada de São Lázaro, 197, Federação Salvador |BA|Brasil CEP 40.210-730 
